\title{
Relationship between red cell distribution width and heart failure
}

\author{
Rudresh M G ${ }^{1}$, Vivek K $\mathbf{U}^{2}$ \\ ${ }^{1}$ Dr. Rudresh M G, Ex-resident, Department of General Medicine, Lady Hardinge Medical College \& Smt S.K. Hospital, \\ New Delhi. ${ }^{2}$ Dr. Vivek KU, Ex resident, Department of Pulmonary Medicine, GMCH, Chandigarh, India.
}

Address for Correspondence: Dr. Vivek KU, Ex resident, Department of Pulmonary Medicine, E-mail: vivek.kotyal@gmail.com

\begin{abstract}
Objective: Red cell distribution width (RDW) has recently been discovered to be a novel prognostic marker in patients with heart failure. There is lack of published reports regarding relationship between RDW and Heart Failure in India. The purpose of this study is to determine whether RDW levels can be used as a prognostic marker in heart failure patients. Materials and Methods: The study was a Cross-sectional study conducted with sample size of 70 subjects with heart failure and 30 subjects without heart failure were selected for the assessment of RDW. Results: The mean RDW in patient was $15.763 \pm 2.609$ and in controls was $13.17 \pm 0.75$ respectively. The RDW was higher in the cases compared to controls with $\mathrm{p}$ value of $<0.001$. Of the 44 patients of HFREF, 33 had RDW> 13.6 and 11 of them had RDW $\leq 13.6$. When compared this distribution of RDW in HFREF with the controls, the difference was significant with a $p$ value of 0.001. Of the 26 patients of HFPEF, 20 had RDW > 13.6 and 6 had RDW $\leq 13.6$. When compared this distribution of RDW with the control group, there was a significant difference with a p value of $<0.001$. Conclusion: RDW is a readily available test and with good prognostic value even when compared with a relatively expensive NT-pro BNP measurement. It can be used as an additional marker for diagnosing heart failure.
\end{abstract}

Keywords: Heart failure, Red cell distribution width, Ejection fraction.

\section{Introduction}

Heart Failure (HF) is the inability of the heart to maintain an output adequate to meet the metabolic demands of the body [1]. The prevalence of heart failure in adult population in developed countries is approximately $1-2 \%$. It is rising to $\geq 10 \%$ among persons aged 70 years or older [2]. The causes of HF are many and these causes vary in different parts of the world. Half of patients with HF have a low EF i.e. heart failure with reduced ejection fraction (HFREF). Coronary artery disease (CAD) is the cause of approximately two-thirds of cases of HFREF. Hypertension and diabetes are contributing factors in many cases. There are many other causes of HFREF, which include previous viral infection, alcohol abuse, chemotherapy (e.g. doxorubicin or trastuzumab) and 'idiopathic' dilated cardiomyopathy [3]. Patients having heart failure with preserved ejection fraction (HFPEF),

Manuscript received: $02^{\text {nd }}$ Jan 2016

Reviewed: $11^{\text {th }}$ Jan 2016

Author Corrected: $23^{\text {rd }}$ Jan 2016

Accepted for Publication: 03 ${ }^{\text {rd }}$ Feb 2016 also known as diastolic heart failure, are older and more often females and obese than those with HFREF (systolic heart failure). They are less likely to have coronary heart disease and more likely to have hypertension and atrial fibrillation (AF). Patients with HFPEF have a better prognosis than those with HFREF [4]. RDW is a quantitative measure of anisocytosis. i.e. the variability in size of the circulating red cells, and is routinely reported by automated laboratory equipment used to perform complete blood counts $(\mathrm{CBC})$ [5]. It is expressed in percentage. Higher RDW values indicate that size of red cell in the given sample of blood vary to a greater extent. RDW is generally used to narrow the differential diagnosis of anaemia. It is used mainly to differentiate iron deficiency anaemia and thalassemia [6]. Recently there has been growing attention given to the relationship between RDW and cardiovascular disorders, such as heart failure and coronary artery disease [7]. Red cell distribution width (RDW) has recently been discovered to be a novel prognostic marker in patients with heart failure. There is only one literature available on the role of RDW in predicting the 
diastolic Heart failure [8]. But it is neither an established diagnostic or prognostic marker in patients with heart failure. There is lack of published reports on relationship between RDW and Heart Failure in India. Also there are no published reports available regarding relationship between RDW and echocardiographic parameters. The purpose of this study is to determine if RDW levels are significantly different in heart failure patients compared to healthy controls.

\section{Materials and Methods}

The study was a Cross-sectional study conducted in the Srimati Sucheta Kriplani Hospital \& Lady Hardinge Medical College and Ram Manohar Lohia Hospital, New Delhi in between November 2012 to march 2014. A sample size of 70 subjects aged over 18 years with heart failure and 30 subjects aged over 18 years without heart failure were selected for the assessment of RDW. Heart failure patients admitted in the medical wards of the hospital as well as those who came to medical OPD for follow up were selected.

Group 1 (cases): Heart failure patients as per inclusion criteria.

Group 2 (controls): Healthy subjects taken randomly from the opd and wards without heart failure.

Inclusion criteria's were 1) Age group 18 and above 2) Follow up cases of heart failure coming in decompensation state of heart failure 3) Newly diagnosed cases of heart failure as per the European society of cardiology criteria[9]: classical symptoms of heart failure with ischemic heart disease, hypertensive heart disease, valvular heart disease and non ischemic cardiomyopathy.

Exclusion criteria's were 1) Refusal of consent 2) Congenital heart diseases 3) Chronic obstructive pulmonary disease 4) Severe anaemia 5) Neoplastic metastasis to bone marrow 6) Pregnancy 7) Severe arthritis 8) Inflammatory bowel disease 9) hypothyroidism 10) Liver diseases.

\section{Aims and Objectives}

\section{Primary}

- To study and compare red cell distribution width between patients of heart failure and healthy subjects.
- To study the relationship between red cell distribution width and echo-cardiographic parameters in patients of heart failure.

- To correlate the red cell distribution of patients with age.

\section{Methodology}

Procedure of performing biochemical investigations: Approximatetly $10 \mathrm{ml}$ of blood was drawn from the patients after informed consent for carrying out routine biochemical tests like, complete blood count (CBC), random blood glucose, liver function tests, kidney function tests, lipid profile. Urine sample was obtained in appropriate container for urine microscopy.

Red Cell Distribution Width: Of the $10 \mathrm{ml}$ of the blood drawn, about $3 \mathrm{ml}$ of the sample was collected in ethylene-diamine-tetra-acetic acid (EDTA) vial for complete blood count. Using SYSMEX KX 21 automated haemotogy analyser (figure 1), various indices of the blood cells were computed and the data was printed. Red cell distribution width was noted from the CBC report.

2-D Echocardiography: using PHILIPS HD 11XE echocardiography machine with $3 \mathrm{~Hz}$ probe, 2-D echocardiography was done within $48 \mathrm{hrs}$ after stabilising the patient. The parameters were recorded as per the American Society of Echocardiography (ASE). Left ventricular ejection fraction was assessed by volume method of Simpson in 2 chamber and 4 chamber view. Doppler parameters 'early diastolic mitral annular velocity' (E), and 'late diastolic mitral annular velocity' (A) were obtained from the apical four-chamber view. Diastolic dysfunction was defined as $\mathrm{E}<\mathrm{A}$, if $\mathrm{E}$ is less than $10 \mathrm{~cm} / \mathrm{s}$ in lateral mitral annulus or less than $8 \mathrm{~cm} / \mathrm{s}$ in septal mitral annulus $[10,11]$.

The criteria for the diagnosis of HFREF or HFPEF are specified. Three criteria (symptoms typical of $\mathrm{HF}+$ signs typical of $\mathrm{HF}+$ reduced LVEF) are required for a diagnosis of HFREF, and four criteria (symptoms typical of $\mathrm{HF}+$ signs typical of $\mathrm{HF}+$ normal or only mildly reduced LVEF and left ventricle not dilated + relevant structural heart disease and/or diastolic dysfunction) are required for a diagnosis of HFPEF [12].

Statistical Analysis: Discrete variables were presented as frequency counts and percentages, whereas 
continuous variables were expressed as mean (standard deviation, SD). The relationship between the two study groups and mean RDW was tested using unpaired t test. The p-value of $<0.05$ was considered statistically significant. The chi-square test was used to compare nominal variables. A P-value of $<0.05$ was considered significant. Correlation between age and RDW was studied in both the group using Spearman's correlation test and $r$ value was calculated. Similar correlation study was done between age and LVEF in cases.

\section{Results}

The present study was conducted in the medical wards of Srimati Sucheta Kriplani Hospital \& Lady Hardinge Medical College and Ram Manohar Lohia Hospital. A total of 70 patients of heart failure and 30 healthy subjects aged above 18 years were included and the following observations and results were obtained. Of the 70 patients of heart failure, 44 $(62.86 \%)$ had reduced ejection fraction and $26(37.14 \%)$ had preserved ejection fraction. The mean age was $52.03 \pm$ 13.21 in controls and $54.86 \pm 11.75$ in the cases. There was no significant difference between the age cases and controls $(\mathrm{p}=0.291)$. There was a female preponderance in the patient group $(58.57 \%)$ whereas males preponderance in the control group (56.67\%). However there was no significant difference between the sex distribution of study group (p=0.161). Of the total 70 patients, 42 had ischemic heart disease; 19 had hypertensive heart disease; 7 had rheumatic heart disease and 2 had nonischemic cardiomyopathy. Of the 29 male patients, 23 had HFREF, whereas among the 41 female patients 21 had HFREF. The Ejection Fraction was significantly lower in male patients compared to female patients with a $p$ value of 0.017. In other words, male patients had more HFREF compared to females.

Among the patients, 41 patients had hypertension, 40 had diabetes and 24 patients were smokers. And among controls none were diabetic or hypertensive however 4 of them were smokers.

Comparison of Red cell distribution width between cases and controls: The mean RDW in patients was $15.763 \pm$ 2.609 and in controls was $13.17 \pm 0.75$ respectively as depicted in table 1 . The red cell distribution width was higher in the cases compared to controls with p value of $<0.001$. Red cell distribution was $>13.6$ in 52 of the 70 cases and $\leq 13.6$ in 18 of the 70 cases. But it was $>13.6$ in only 4 of the 30 controls and $\leq 13.6$ in 26 of the 30 controls. This difference is significant with a $\mathrm{p}$ value of $<0.001$. This is depicted in table 2 .

Table-1: Frequency distribution of RDW in the study group

\begin{tabular}{|l|l|l|}
\hline Frequency distribution & Controls & Cases \\
\hline Mean & 13.17 & 15.76 \\
\hline Median & 13 & 15.4 \\
\hline Std. Deviation & 0.755 & 2.609 \\
\hline
\end{tabular}

Table-2: Comparison of RDW between controls and cases

\begin{tabular}{|l|l|l|l|l|l|}
\hline \multicolumn{2}{|c|}{} & \multicolumn{2}{|l|}{ Red cell distribution width } & \multirow{2}{*}{ Total } & \multirow{2}{*}{ p value } \\
\cline { 3 - 4 } \multicolumn{2}{|c|}{} & $\mathbf{S 1 3 . 6}$ & $\mathbf{> 1 3 . 6}$ & & \\
\hline \multirow{3}{*}{ Group } & Controls & 26 & 4 & 30 & $<0.001$ \\
\cline { 2 - 4 } & Cases & 18 & 52 & 70 & \\
\hline Total & $\mathbf{4 4}$ & $\mathbf{5 6}$ & $\mathbf{1 0 0}$ & \\
\hline
\end{tabular}

Of the 44 patients of HFREF, 33 had red cell distribution width $>13.6$ and 11 of them had RDW $\leq 13.6$. When compared this distribution of RDW in HFREF with the controls, the difference was significant with a p value of 0.001 . Of the 26 patients of HFPEF, 20 had RDW > 13.6 and 6 had RDW $\leq 13.6$. When compared this distribution of RDW with the control group, there was a significant difference with a $\mathrm{p}$ value of $<0.001$.

Comparison of RDW between HFREF and HFPEF: 11 of the 44 patients of HFREF had RDW $\leq 13.6$ and 33 of them had RDW >13.6. 6 of the 26 patients of HFPEF had RDW $\leq 13.6$ and 20 had RDW > 13.6. There was no significant difference in the distribution of RDW between these two subgroups of heart failure population. They were comparable with a $\mathrm{p}$ value of 0.856 . This is depicted in table 3 - 
Table-3: Comparison of RDW between two subgroups of Heart Failure

\begin{tabular}{|l|l|l|l|l|l|}
\hline \multicolumn{2}{|c|}{} & \multicolumn{2}{|l|}{ RDW } & \multirow{2}{*}{ Total } & \multirow{2}{*}{ P value } \\
\cline { 3 - 5 } \multicolumn{2}{|c|}{} & $\mathbf{S 1 3 . 6}$ & $\mathbf{> 1 3 . 6}$ & & \multirow{2}{*}{0.856} \\
\cline { 2 - 5 } Subgroup & HFREF & 11 & 33 & 44 & \\
\cline { 2 - 5 } & HFPEF & 6 & 20 & $\mathbf{7 0}$ & \\
\hline
\end{tabular}

Of the 17 patients of heart failure with E/A <1, 13 had RDW > 13.6, and of the 53 patients of HF with normal E/A ratio, RDW was elevated in 40. This difference between the two groups was not significant ( $\mathrm{p}$ value $=0.933$ ).

Correlation between RDW and LVEF: There was no correlation between the RDW and LVEF with r value of 0.017 and $\mathrm{p}$ value of 0.890 . The scattered diagram in figure depicts the correlation between the two variables. Correlation matrices for variables related to RDW and LVEF are shown in table 4 and figure 2.

Table 4: correlation between RDW and LVEF in Cases:

\begin{tabular}{|l|l|l|}
\hline \multirow{2}{*}{ RDW vs LVEF } & Pearson correlation 'r' & 0.017 \\
\cline { 2 - 3 } & P value & 0.89 \\
\cline { 2 - 3 } & $\mathrm{N}$ & 70 \\
\hline
\end{tabular}

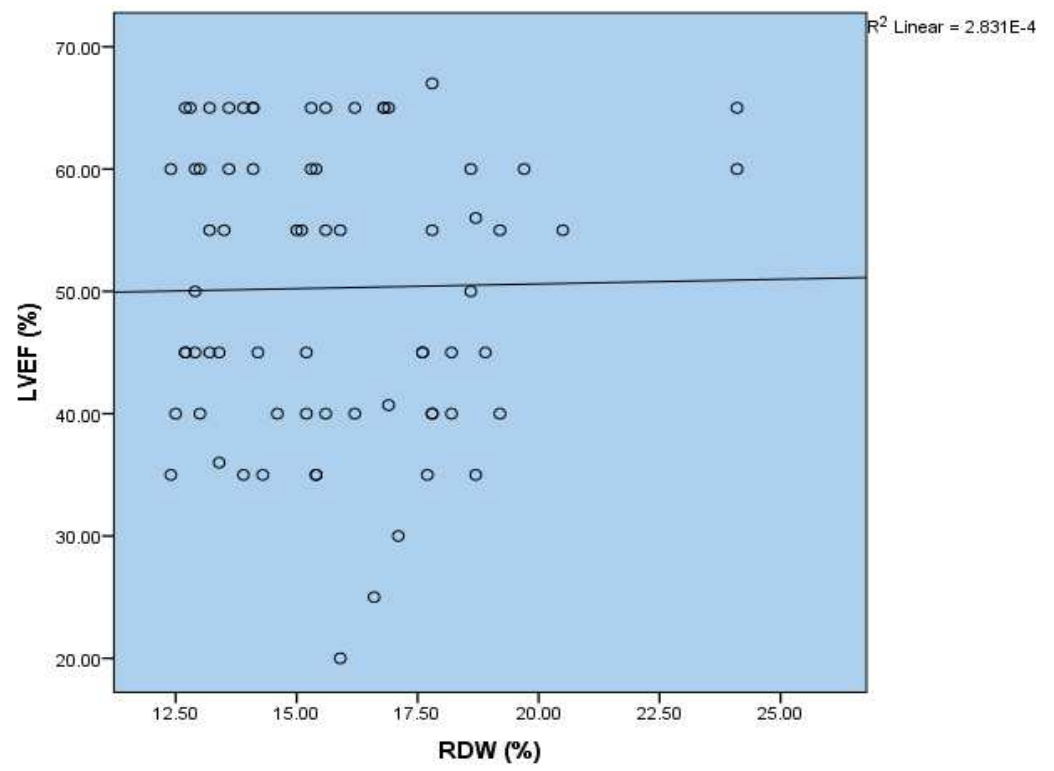

Figure 2: Scatter diagram showing correlation between LVEF and RDW

A significant negative correlation was observed between age of the cases and their red cell distribution width $(r=-0.338$, $\mathrm{p}<0.004)$. This indicates that lower age is associated with a higher value of red cell distribution width and vice versa. There was no correlation between the age of the controls with their red cell distribution width. The $r$ value was -0.228 with a $p$ value of 0.226 . A strong negative correlation was found between the age of patients and their LVEF ( $r=0.241, p$ $=0.045)$, as the age of the patients increased, their LVEF was decreased.

\section{Discussion}

The hypothesis of the study was "higher level of red cell distribution width is associated with heart failure with reduced ejection fraction as well as heart failure with preserved ejection fraction in the age group 18-75 years at the time of presentation to hospital in comparison to normal population". Recently, RDW has been shown to be a novel marker for predicting outcomes in the heart failure population.[7, 13,14]. The cause of elevated RDW in heart failure patients has been attributed to inflammation, ineffective 
erythropoiesis, malnutrition, impaired renal function and neurohormonal activation [14].

The age of patients varied from 20 to 80 years, with a mean of 55 years. Heart failure can occur in any age group. Valvular heart disease, mostly rheumatic and nonischemic cardiomyopathy involved younger age group where as hypertensive heart disease and ischemic heart disease involved older age group. The mean age of our cases and controls were comparable. It is similar to the study done by Atac Celik et al [8] for diastolic heart failure patients where Seventy-one patients (mean age, $57 \pm 7$ years) and 50 controls (mean age, $56 \pm 7$ years) were included.

Of the 70 patients of heart failure, 41 were females and 29 were males. Heart failure involved more females compared to males. The valvular heart disease involved only females in our study and hence there was a female preponderance. This is in contrast to many other studies. This difference in the sex distribution may be because of difference in the admissions pattern in various hospital centres. The lifetime risk of developing $\mathrm{HF}$ at the age of $40 \mathrm{yr}$ is 11.4 per cent for men and 15.4 per cent for women [15]. This may explain the female prepondenderance of heart failure in our study. But in the study done by Atac Celik et al $63 \%$ were women and the incidence of HFREF was more in males than in females. Their study is supported by in the Metaanalysis Global Group in Chronic Heart Failure (MAGGIC) study 2012 where the incidence of HFREF is more in males and HFPEF is more in females [16]. Of the 70 patients, $42(60 \%)$ had ischemic heart disease, 19 had hypertensive heart disease, 7 had rheumatic heart disease and 2 had nonischemic cardiomyopathy. This in consistent with the study by Yahya Al-Najjar et al where the aetiology of the HF was mostly ischemic (70\%) [17]. In India coronary artery disease, diabetes,

hypertension, valvular heart diseases and primary muscle diseases are the leading causes for heart failure. Rheumatic heart disease is still a common cause of heart failure in India [12]. Our study included all of the above etiologies. Felker et al [7] showed that RDW was an independent predictor of morbidity and mortality in two large cohort study of CHF patients. The first cohort was from the CHARM program of candesartan or placebo in patients with stable CHF. The second cohort was obtained from the Duke Databank (a clinical database at Duke University Medical Center that includes all patients that have undergone cardiac catheterization). The studies done by Atac Celik et al
[8] showed that RDW is elevated in patients of Diastolic heart failure. Our study has shown that RDW is elevated in patients of both systolic (HFREF) as well as diastolic heart failure population (HFPEF).

Red cell distribution width is a measure of variation in red blood cell size in a blood sample. It is calculated by impedance analyser as part of the routine complete blood count. It is calculated as RDW $=(\mathrm{SD}$ of red cell volume/mean cell volume) $\times 100$. Higher RDW values mean a greater variety of cell sizes are present. The normal range for RDW is between 11.5 and $14.5 \%$ [18]. In the study conducted by Atac celik et al, the cut off for the RDW for predicting heart failure was found to be as 13.6. So our study divided the patients into those having $\mathrm{RDW} \leq 13.6$ and those having $>13.6$.

Red cell distribution width is used to classify anaemia. It is also used in detection of early iron and folate deficiency. Higher RDW values have been shown to be independently related to increased mortality and cardiovascular events in people with previous myocardial infarcts or strokes. It has also been described as one of indicators of ulcerative colitis activity along with c- reactive protein and erythrocyte sedimentation rate.

The cause of the elevated RDW in these disorders is still not clear. In patients of heart failure increase in RDW may be because of impaired bone marrow function or increased red cell destruction. As inflammation is an established mechanism in heart failure, it could be a reason for elevated RDW seen these patients. Inflammatory cytokines have been shown to be prognostic in HF. The study done by Atac Celik et al suggests that high RDW levels in patients with heart failure may be related to increased neurohormonal activity, impaired renal functions, and elevated filling pressure, but not to increased inflammation. So, further studies are required to solve the underlying mechanism for the RDW increase in this population. The left ventricular ejection fraction was noted from the echo report of the patients and they were divided into HFPEF and HFREF subgroups. Patients with $\mathrm{EF} \leq 50 \%$ were grouped into HFREF and those with EF > 50\% were grouped into HFPEF (DHF). [19] Of the 70 patients $44(62.85 \%)$ patients had HFREF and remaining 26(37.15) had HFPEF. But there was a difference between males and females with regard to classification. Of the 29 male patients, the LVEF was lower in 23 whereas among the 41 females patients it was lower in 21 . The $\mathrm{p}$ value for this difference was 
0.017. This difference between males and females may be due to by chance as there is no explanation for this in the literature.

E stands for 'Early diastolic mitral annular velocity' and A stands for 'late diastolic mitral annular velocity'. E/A ratio is helpful in defining Diastolic dysfunction. If $\mathrm{E}<$ $\mathrm{A}$, and $\mathrm{E}$ is less than $10 \mathrm{~cm} / \mathrm{s}$ in lateral mitral annulus or less than $8 \mathrm{~cm} / \mathrm{s}$ in septal mitral annulus, there is said to be diastolic dysfunction. In our patients $\mathrm{E} / \mathrm{A}$ ratio was seen in all the patients. E/A ratio of $<1$ was present more in HFPEF compared to HFREF. The difference was significant with a $\mathrm{p}$ value of 0.033 . This could be due to high prevalence of diastolic dysfunction in patients with HFPEF compared to HFREF. This, in turn, could be due to increased coexistence of hypertension in the patients with HFPEF (17 out of 26).

The present study had some limitations, Erythropoietin level (EPO) is an independent prognostic marker in HF patients (even in the presence of BNP) [20]. Further works is needed to ensure that RDW is independent of EPO levels. As RDW is a readily available test, red cell distribution width is a readily available test in the HF population. It is effectively a 'free' test (it is reported alongside a full blood count at no extra cost) with good prognostic value even when compared with a relatively expensive NT-pro BNP measurement.

\section{Conclusions}

Red cell distribution width is a readily available test. As it is reported alongside a complete blood count, no additional cost is incurred in knowing it. It is a good marker with good prognostic value even when compared with a relatively expensive NT-proBNP measurement. It can be used as an additional marker for diagnosing heart failure.

\section{Funding: Nil}

Conflict of interest: None.

Permission of IRB: Yes

\section{Referrences}

1. Brian R. Lindman, Stay A. Mandras, Benico Barzilai, Susan M. Joseph and Gregory A. Ewald. The Washington Manual of Medical Therapeutics. 33rd edition ; p155.

2. Mosterd A, Hoes AW. Clinical epidemiology of heart failure. Heart. 2007 Sep; 93(9):1137-46.
3. Ackerman MJ, Priori SG, Willems S, Berul C, Brugada R, Calkins $\mathrm{H}$ et al. HRS/EHRA expert consensus statement on the state of genetic testing for the channelopathies and cardiomyopathies. Europace. 2011 Aug; 13(8):1077-109. doi: 10.1093/europace/eur245.

4. Meta-analysis Global Group in Chronic Heart Failure (MAGGIC). The survival of patients with heart failure with preserved or reduced left ventricular ejection fraction: an individual patient data meta-analysis. Eur Heart J 2012; 33; p1750-1757.

5. M. Morris, F. R. Davey. Basic examination of blood J.B. Henry. Clinical diagnosis and management by laboratory methods (2001), pp.489-499.

6. S.D. Mckenzie. Introduction to anaemia S.D Mckenzie(Ed.), Clinical laboratory haematology, Pearson Pretice-Hall, Saddle River, (2008) pp. 188.

7. Felker GM, Allen LA, Pocock SJ, Shaw LK, McMurray JJ, Pfeffer MA, Swedberg K, Wang D, Yusuf S, Michelson EL, Granger CB; CHARM Investigators. Red cell distribution width as a novel prognostic marker in heart failure: data from the CHARM Program and the Duke Databank. J Am Coll Cardiol. 2007 Jul 3; 50(1):40-7. Epub 2007 Jun 18.

8. Celik A, Koc F, Kadi H, Ceyhan K, Erkorkmaz U, Burucu T, Karayakali M, Onalan O. Relationship between red cell distribution width and echocardiographic parameters in patients with diastolic heart failure. Kaohsiung J Med Sci. 2012 Mar; 28(3):165-72. doi: 10.1016/j.kjms.2011.06.024. Epub 2011 Sep 17.

9. McMurray JJ1, Adamopoulos S, Anker SD, Auricchio A, Böhm M, Dickstein K, et al. ESC Guidelines for the diagnosis and treatment of acute and chronic heart failure 2012: The Task Force for the Diagnosis and Treatment of Acute and Chronic Heart Failure 2012 of the European Society of Cardiology. Developed in collaboration with the Heart Failure Association (HFA) of the ESCEur Heart J. 2012 Jul; 33(14):1787-847. doi: 10.1093/eurheartj/ehs104.

10. Roger VL, Go AS, Lloyd-Jones DM, Benjamin EJ, Berry JD, Borden WB, Bravata DM, Dai S, Ford ES, Fox CS, Fullerton HJ, Gillespie C, Hailpern SM, Heit JA,Howard VJ, Kissela BM, Kittner SJ, Lackland DT, Lichtman JH, Lisabeth LD, Makuc DM, Marcus GM, Marelli A, Matchar DB, Moy 
CS, Mozaffarian D, Mussolino ME, Nichol G, Paynter NP, Soliman EZ, Sorlie PD, Sotoodehnia N, Turan TN, Virani SS, Wong ND, Woo D, Turner MB; American Heart Association Statistics Committee and Stroke Statistics Subcommittee. Heart disease and stroke statistics--2012 update: a report from the American Heart Association. Circulation. 2012 Jan 3;125(1):e2-e220. doi: 10.1161/CIR.0b013e31823ac046. Epub 2011 Dec 15.

11. Chen J, Normand SL, Wang Y, Krumholz HM. National and regional trends in heart failure hospitalization and mortality rates for Medicare beneficiaries, 1998-2008. JAMA. 2011 Oct 19;306(15):1669-78. doi: 10.1001/jama.2011.1474.

12. McMurray JJ, Adamopoulos S, Anker SD, Auricchio A, Böhm M, et al. ESC Guidelines for the diagnosis and treatment of acute and chronic heart failure 2012: The Task Force for the Diagnosis and Treatment of Acute and Chronic Heart Failure 2012 of the European Society of Cardiology. Eur J Heart Fail. 2012 Aug;14(8):803-69.

13. Rdw1. Förhécz Z, Gombos T, Borgulya G, Pozsonyi Z, Prohászka Z, Jánoskuti L. Red cell distribution width in heart failure: prediction of clinical events and relationship with markers of ineffective erythropoiesis, inflammation, renal function, and nutritional state. Am Heart J. 2009;158:659-666.

14. Al-Najjar Y, Goode KM, Zhang J, Cleland JG, Clark AL. Red cell distribution width: an inexpensive and powerful prognostic marker in heart failure. Eur J Heart Fail. 2009 Dec; 11(12):1155-62. doi: 10.1093/eurjhf/hfp147.
15. S. Reddy, A. Bahl, and K.K. Talwar; Congestive heart failure in Indians: How do we improve diagnosis \& management? ; Indian J Med Res. Nov 2010; 132(5): 549-560.

16. Meta-analysis Global Group in Chronic Heart Failure (MAGGIC). The survival of patients with heart failure with preserved or reduced left ventricular ejection fraction: anindividual patient data metaanalysis. Eur Heart J. 2012 Jul;33(14):1750-7. doi: 10.1093/eurheartj/ehr254. Epub 2011 Aug 6.

17. Al-Najjar Y, Goode KM, Zhang J, Cleland JG, Clark AL. Red cell distribution width: an inexpensive and powerful prognostic marker in heart failure. Eur J Heart Fail. 2009 Dec;11(12):1155-62. doi: 10.1093/eurjhf/hfp147.

18. Das Gupta A, Hegde C, Mistri R. Red cell distribution width as a measure of severity of iron deficiency in iron deficiency anaemia. Indian J Med Res. 1994 Oct;100:177-83.

19. Förhécz Z1, Gombos T, Borgulya G, Pozsonyi Z, Prohászka Z, Jánoskuti L. Red cell distribution width in heart failure: prediction of clinical events and relationship with markers of ineffective erythropoiesis, inflammation, renal function, and nutritional state. Am Heart J. 2009 Oct;158(4):659-66. doi: 10.1016/j.ahj.2009.07.024. Epub 2009 Aug 26.

20. Popescu BA, Andrade MJ, Badano LP, Fox KF, Flachskampf FA et al. European Association of Echocardiography recommendations for training, competence, and quality improvement in echocardiography. Eur J Echocardiogr 2009;10:893-905

\section{How to cite this article?}

Rudresh M G, Vivek K U. Relationship between red cell distribution width and heart failure. Int J Med Res Rev 2016;4(2):144-150. doi: 10.17511/ijmrr.2016.i02.003. 